Clinical Technique

\title{
Dip Quick Staining Modified for Morphological Evaluation to Equine Spermatozoa
}

\section{Lorenzo Garrido Segabinazzi, Luis Fernando Mercês Chaves, Endrigo Adonis Araujo, Sidnei Nunes de Oliveira, Luiz Roberto Pena de Andrade Junior, Carolina Tieme Cardoso Okada, Veridiana de Paula Andrade, Camila de Paula Freitas Dell'Aqua, Frederico Ozanam Papa, Marco Antonio Alvarenga*}

Department of Animal Reproduction and Veterinary Radiology, São Paulo State University, UNESP, Botucatu, 18.618-970, Brazil

\section{A R T I C L E I N F O}

\section{Article history:}

Received 31 October 2016

Received in revised form 19 February 2017

Accepted 23 February 2017

Available online 30 March 2017

\section{Keywords:}

Dip Quick stain

Equine spermatozoa

Morphology

Semen

Stallion

\begin{abstract}
A B S T R A C T
Morphological analysis of the sperm cells were accomplished from 19 stallions comparing six different techniques (DIC, Karras, Eosin-Nigrosin, Dip Quick 5', Dip Quick modified, Dip Quick) in order to verify the possibility of using a modification of Dip Quick stain technique to evaluate the morphology of equine semen. Data of sperm morphology were evaluated using Kolmogorov-Smirnov (KS) normality test. Parametric continuous data were compared for ANOVA followed by the Tukey test and non-parametric dates, for KruskalWallis test followed by the Dunns test. Significant differences were considered when $P<.05$. Pearson product-correlation procedure was used to test the correlation between technics. High correlation were considered when $r \geq 0.7$, moderate correlation when $r \geq 0.5$ but $r<0.7$ and poor correlation when $r<0.5$. The proposed technique did not show difference $(P>.05)$ from other techniques to morphological assessment. However, the usual Dip quick technique showed to be less efficient $(P<.05)$ to evaluated the sperm morphology defects, especially for the display of abnormal heads, distal and proximal droplets. A High correlation was observed among techniques in the evaluation of total number of defects, but when specific sperm defects of each segment were measured the Dip Quick modified showed a high correlation compared with the usual technics, different results from the Dip Quick technic that showed a moderate correlation on the evaluation of distal and proximal droplets and poor correlation on abnormal heads evaluation. We can conclude that the modification of the Dip Quip technique improved the quality of smear for the evaluation of equine sperm morphology.
\end{abstract}

(c) 2017 Elsevier Inc. All rights reserved.

\footnotetext{
Ethical approval statement: All procedures were approved by the animal care committee from Veterinary School of University of São Paulo State UNESP - Botucatu process number 028/2016.

* Corresponding author at: Marco Antonio Alvarenga, PhD, Departamento de Reprodução Animal e Radiologia Veterinária, FMVZ, UNESP, Distrito de Rubião Junior, s/nº $18618-970$, Botucatu, SP, Brazil.

E-mail address: malvarenga@fmvz.unesp.br (M.A. Alvarenga).
}

\section{Introduction}

The breeding soundness examination is essential to predict the stallion reproductive capacity. The evaluation of sperm morphology is one of the laboratory practices which can be used to estimate this ability in men, because the high frequency of morphologically abnormal cells or the high incidence of a single defect may reduce the fertility of these animals [1]. Furthermore, the acquaintance of the spermatic aberrations and the spermatogenesis process are 
Table 1

Averages of sperm morphological defects according to the technique used.

\begin{tabular}{lcccccc}
\hline $\begin{array}{l}\text { Morphological } \\
\text { Defects }\end{array}$ & DIC & Karras & E/N & $\begin{array}{l}\text { Dip } \\
\text { Quick 5 }\end{array}$ & $\begin{array}{l}\text { Dip Quick } \\
\text { Modified }\end{array}$ & $\begin{array}{l}\text { Dip } \\
\text { Quick }\end{array}$ \\
\hline Normal & $66.3^{\mathrm{a}}$ & $69.5^{\mathrm{ab}}$ & $69.9^{\mathrm{ab}}$ & $73.6^{\mathrm{ab}}$ & $68.9^{\mathrm{ab}}$ & $78.3^{\mathrm{b}}$ \\
Abnormal heads & $5.4^{\mathrm{a}}$ & $4.3^{\mathrm{ab}}$ & $3.7^{\mathrm{abc}}$ & $2.9^{\mathrm{bc}}$ & $4.2^{\mathrm{ab}}$ & $2.2^{\mathrm{c}}$ \\
Abnormal middle & $3.4^{\mathrm{a}}$ & $2.7^{\mathrm{a}}$ & $2.8^{\mathrm{a}}$ & $2.2^{\mathrm{a}}$ & $2.8^{\mathrm{a}}$ & $0.9^{\mathrm{b}}$ \\
$\quad$ piece & & & & & & \\
Pathologies tail & 15.4 & 15.3 & 14.6 & 14.3 & 15.1 & 13.4 \\
$\quad$ and tail insert & & & & & & \\
Proximal droplet & $5.1^{\mathrm{a}}$ & $3.9^{\mathrm{a}}$ & $4.1^{\mathrm{a}}$ & $1.5^{\mathrm{b}}$ & $4.3^{\mathrm{a}}$ & $1.0^{\mathrm{b}}$ \\
Distal droplet & $2.8^{\mathrm{a}}$ & $2.7^{\mathrm{a}}$ & $2.8^{\mathrm{a}}$ & $1.8^{\mathrm{ab}}$ & $2.6^{\mathrm{a}}$ & $0.9^{\mathrm{b}}$ \\
Detached head & $1.8^{\mathrm{ab}}$ & $1.7^{\mathrm{b}}$ & $2.1^{\mathrm{ab}}$ & $3.6^{\mathrm{a}}$ & $2.1^{\mathrm{ab}}$ & $3.3^{\mathrm{ab}}$ \\
All defects & $33.7^{\mathrm{a}}$ & $30.5^{\mathrm{ab}}$ & $30.1^{\mathrm{ab}}$ & $26.4^{\mathrm{ab}}$ & $31.1^{\mathrm{ab}}$ & $21.7^{\mathrm{b}}$ \\
Acrosome & $7.3^{\mathrm{a}}$ & $6.7^{\mathrm{a}}$ & $0.0^{\mathrm{c}}$ & $0.0^{\mathrm{c}}$ & $2.1^{\mathrm{b}}$ & $0.0^{\mathrm{c}}$ \\
\hline
\end{tabular}

Abbreviations: DIC, differential interference contrast microscopy; E/N, Eosin Negrosin; Karras, Karras modified stain.

Lowercase letters indicate statistical difference between the columns $(P<.05)$.

essential for diagnosis and adequate clinical management of stallions with reproductive pathologies [2].

As the sperm is a translucent cell, its visualization under bright field microscopy is not evident for the cell outline evaluation. Therefore, when you have only this method, the stained smear technique should be used [1,3]. Semen evaluation may also be performed by the humid chamber with the assistance of phase-contrast microscopy or differential interference contrast (DIC) microscopy in which it is not necessary that the sperm cell be stained $[3,4]$.

The Dip Quick is a staining technique commonly used in the medical and veterinary routine for staining cytological slides and blood smears, it is easily obtainable in addition to be inexpensive. However, when using this technique for performing sperm cells smears, the visualization is very poor [5], prejudicing the examination. The aim of this study is to investigate the possibility of using the Dip Quick Stain to evaluate equine sperm morphology.

\section{Material and Method}

\subsection{Animals}

For the present study, one ejaculate from 19 stallions of different breeds (Brazilian Equestrian, Lusitano, Mangalarga

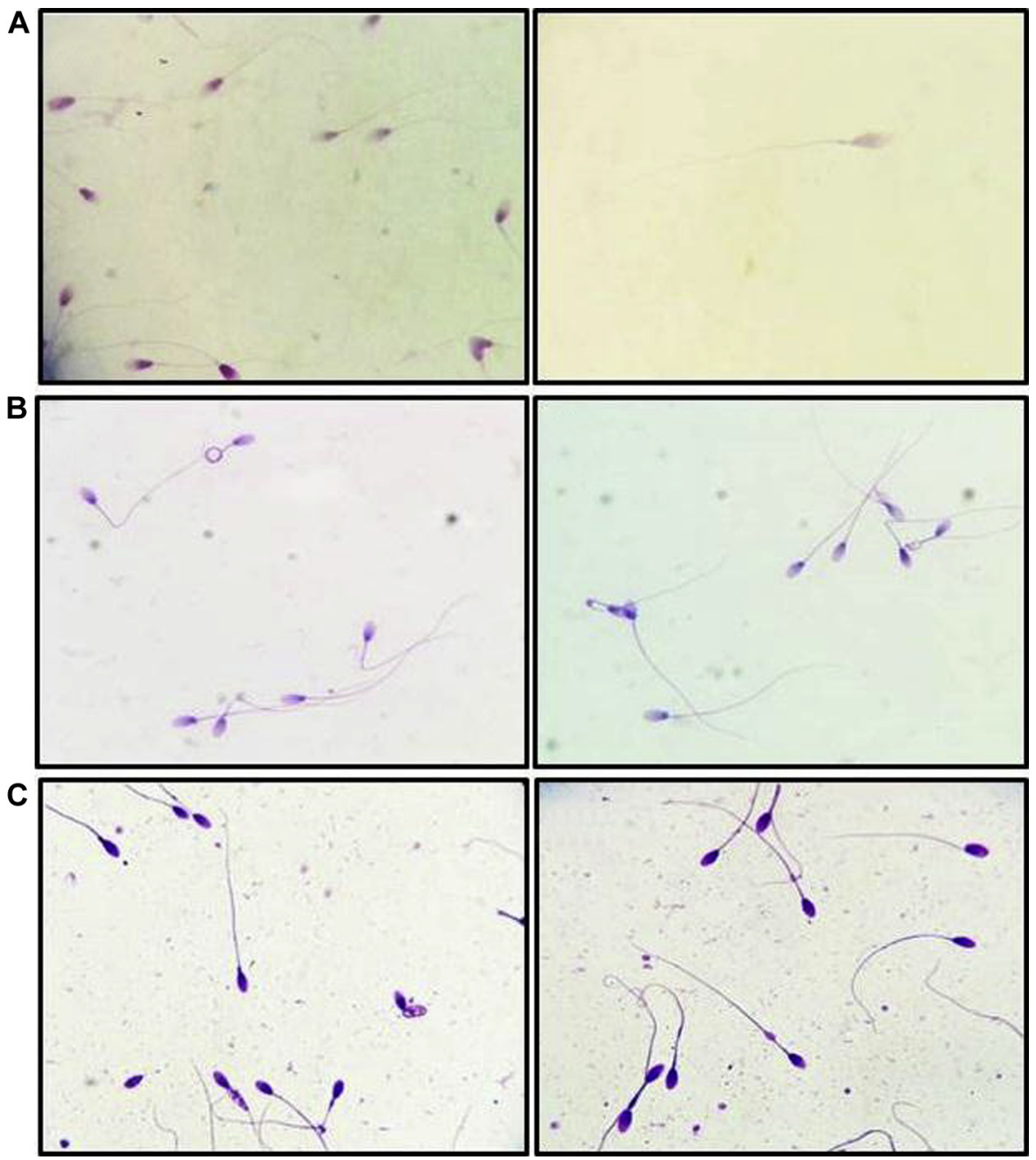

Fig. 1. Images of equine semen evaluated using Dip Quick Stain and bright-light microscopy with different staining techniques. (A) Dip Quick; (B) Dip Quick 5"; and (C) Dip Quick Modified. 
Marchador) were obtained with various fertility rates, belonging to Ogar (Private stud farm, Lins, SP, Brazil), Itapuã (Private stud farm, Arandú, SP, Brazil), and the Department of Animal Reproduction and Veterinary Radiology of UNESP, Botucatu.

\subsection{Sampling Strategy and Slides Staining}

Semen collection was performed with artificial vagina model Botupharma (Botupharma LTDA, Botucatu, Brazil). After the semen collection, the gel fraction was removed by filtering with a nylon mesh filter. Five aliquots of pure semen were separated from each stallion for further smears and a sixth aliquot was diluted in $10 \%$ formol saline for evaluation in DIC microscopy (Leica Microsystems, Wetzlar, Alemanha).

Five smears of each stallion were prepared on microscope slides and stained individually with the respective technique: smear 1 (Karras)-modified Karras stain [6]; smear 2 (E/N)-Eosin Negrosin stain (Hancock Stain, Animal Reproduction Systems [ARS] EUA) [7]; smear 3 (Dip Quick)-Dip Quick Stain (Instant Prov; Newprov, Brazil); smear 4 (Dip Quick 5')-Dip Quick 5' Stain, using 5 minute immersion in each stain [8]; and smear 5 (Dip Quick modified)-modification of the staining technique by Dip Quick 5' without washing after each stain.

To execute the proposed technique (Dip Quick Modified), in the present study, the smears were first dry at $37^{\circ} \mathrm{C}$. After drying, the slides were immersed for 10 seconds in fixative solution (solution I of Dip Quick, Instant Prov; Newprov), then passed to the second stain (solution II of the kit) where they remained for 5 minutes and similarly with the third stain (solution III of the kit). Following each staining step, the excess of stain was removed from the slides without the usual washing, positioning them vertically supported on a paper towel to facilitate stain drainage and immediately plunged into the next stain. At the end of the procedure, the smears were dried at room temperature, left under the same vertical support.

\subsection{Slides Evaluation}

A bright-field microscopy was used for the smears analysis, at $1,000 \times$ optical lens with immersion oil. To evaluate the DIC, wet-mount of each preparation was mounted using a drop of diluent sample in saline formaldehyde between slide and coverslip and viewed at 1,000× magnification using immersion oil.

The evaluation of the smears was conducted by the same experienced assessor without the slides identification, in a blind evaluation method. A total of 100 spermatozoa in each sample were counted and classified as morphologically normal or abnormal.

The defects were divided into head defects (underdeveloped, giant, contour defects, pouch formation, diadem defect, knobbed), intermediate piece defects (edema or fracture), proximal cytoplasmic droplet, distal cytoplasmic droplets, and defects of tail and insert defects (coiled, strongly folded or rolled, wrapped in the head, retro and abaxial, oblique, folded with droplet).
The acrosome defects (no acrosome or detached) were evaluated separately from others, taking into account the number of cells with this pathology/100 cells.

\subsection{Statistical Analysis}

Data of sperm morphology were evaluated using Kolmogorov-Smirnov normality test, to test its Gaussian distribution. Parametric continuous data were compared for analysis of variance followed by the Tukey test and nonparametric dates, for Kruskal-Wallis test followed by the Dunn test. Significant differences were considered when $P<.05$. The degrees of linear correlations between

Table 2

Correlation of sperm morphology results among the different techniques.

\begin{tabular}{|c|c|c|c|c|c|}
\hline Technique & DIC & Karras & $\mathrm{E} / \mathrm{N}$ & $\begin{array}{l}\text { Dip } \\
\text { Quick 5' }\end{array}$ & $\begin{array}{l}\text { Dip Quick } \\
\text { Modified }\end{array}$ \\
\hline \multicolumn{6}{|l|}{ Normal } \\
\hline DIC & 1.0 & & & & \\
\hline Karras & 0.9862 & 1.0 & & & \\
\hline $\mathrm{E} / \mathrm{N}$ & 0.9263 & 0.9240 & 1.0 & & \\
\hline Dip Quick 5" & 0.8663 & 0.8718 & 0.9375 & 1.0 & \\
\hline Dip Quick Modified & 0.9604 & 0.9537 & 0.9556 & 0.9497 & 1.0 \\
\hline Dip Quick & 0.8240 & 0.8401 & 0.8901 & 0.8969 & 0.8980 \\
\hline \multicolumn{6}{|l|}{ Abnormal heads } \\
\hline DIC & 1.0 & & & & \\
\hline Karras & 0.9163 & 1.0 & & & \\
\hline $\mathrm{E} / \mathrm{N}$ & 0.8503 & 0.8000 & 1.0 & & \\
\hline Dip Quick 5" & 0.6230 & 0.4778 & 0.4711 & 1.0 & \\
\hline Dip Quick Modified & 0.9104 & 0.8474 & 0.8239 & 0.5788 & 1.0 \\
\hline Dip Quick & 0.1233 & 0.0809 & 0.0222 & 0.1402 & 0.0308 \\
\hline \multicolumn{6}{|l|}{ Abnormal midpieces } \\
\hline DIC & 1.0 & & & & \\
\hline Karras & 0.9123 & 1.0 & & & \\
\hline $\mathrm{E} / \mathrm{N}$ & 0.8249 & 0.7154 & 1.0 & & \\
\hline Dip Quick 5" & 0.7946 & 0.8470 & 0.6915 & 1.0 & \\
\hline Dip Quick Modified & 0.9027 & 0.8830 & 0.6963 & 0.8711 & 1.0 \\
\hline Dip Quick & 0.7201 & 0.6815 & 0.7067 & 0.7999 & 0.8562 \\
\hline \multicolumn{6}{|l|}{ Tail defects } \\
\hline DIC & 1.0 & & & & \\
\hline Karras & 0.9900 & 1.0 & & & \\
\hline $\mathrm{E} / \mathrm{N}$ & 0.9377 & 0.9192 & 1.0 & & \\
\hline Dip Quick 5" & 0.9306 & 0.9065 & 0.9623 & 1.0 & \\
\hline Dip Quick Modified & 0.9780 & 0.9609 & 0.9682 & 0.9591 & 1.0 \\
\hline Dip Quick & 0.8982 & 0.8712 & 0.9204 & 0.9584 & 0.9383 \\
\hline \multicolumn{6}{|l|}{ Proximal droplets } \\
\hline DIC & 1.0 & & & & \\
\hline Karras & 0.9519 & 1.0 & & & \\
\hline $\mathrm{E} / \mathrm{N}$ & 0.9663 & 0.9200 & 1.0 & & \\
\hline Pozor $5^{\prime \prime}$ & 0.6527 & 0.6529 & 0.6516 & 1.0 & \\
\hline Dip Quick Modified & 0.9503 & 0.9423 & 0.9318 & 0.7688 & 1.0 \\
\hline Dip Quick & 0.6436 & 0.6843 & 0.6342 & 0.5350 & 0.6218 \\
\hline \multicolumn{6}{|l|}{ Distal droplets } \\
\hline DIC & 1.0 & & & & \\
\hline Karras & 0.9591 & 1.0 & & & \\
\hline $\mathrm{E} / \mathrm{N}$ & 0.9153 & 0.8861 & 1.0 & & \\
\hline Dip Quick 5" & 0.8409 & 0.8602 & 0.7100 & 1.0 & \\
\hline Dip Quick Modified & 0.9432 & 0.9293 & 0.8741 & 0.8301 & 1.0 \\
\hline Dip Quick & 0.6739 & 0.7625 & 0.6475 & 0.5759 & 0.7681 \\
\hline \multicolumn{6}{|l|}{ Tailless heads } \\
\hline DIC & 1.0 & & & & \\
\hline Karras & 0.9621 & 1.0 & & & \\
\hline $\mathrm{E} / \mathrm{N}$ & 0.9749 & 0.9752 & 1.0 & & \\
\hline Dip Quick 5" & 0.9360 & 0.9048 & 0.9453 & 1.0 & \\
\hline Dip Quick Modified & 0.9653 & 0.9597 & 0.9706 & 0.9332 & 1.0 \\
\hline Dip Quick & 0.8542 & 0.8762 & 0.8970 & 0.8961 & 0.9227 \\
\hline
\end{tabular}

Abbreviations: DIC, differential interference contrast microscopy; E/N, Eosin Negrosin; Karras, Karras modified stain. 

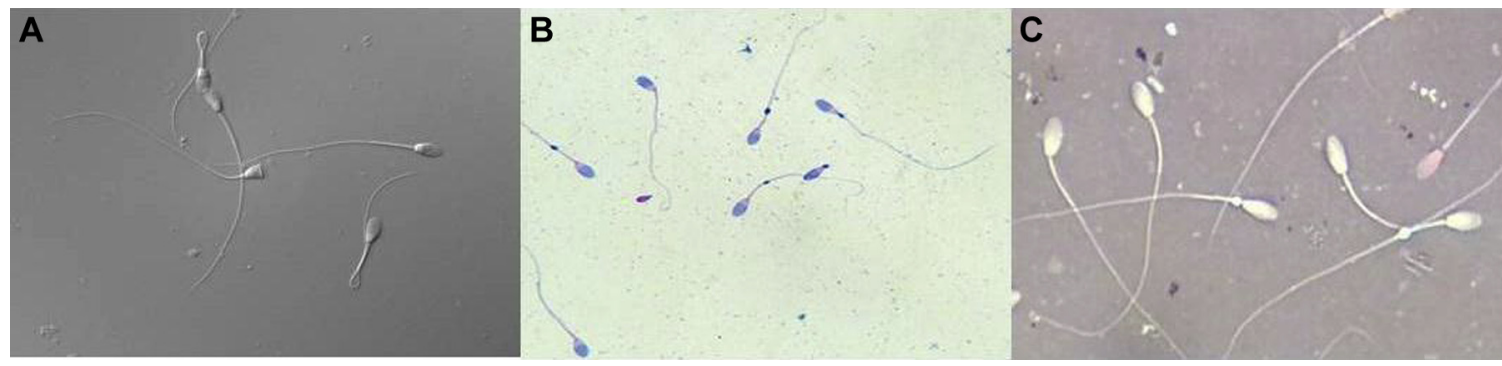

Fig. 2. Classical methods for equine semen evaluation (magnification 1,000×). (A) Differential interference contrast microscopy; (B) Karras modified staining; and (C) Eosin Negrosin staining.

methodologies were tested using Pearson productcorrelation procedure. High correlation was considered when $r \geq 0.7$, moderate correlation when $r \geq 0.5$ but $r<0.7$, and poor correlation when $r<0.5$.

\section{Results}

The Dip Quick Stain technique showed to be less efficient $(P<.05)$ in the observation of morphology defects (Table 1) when compared with the other studied techniques.

When specific spermatic morphological defects of each segment were evaluated, there were significant differences between the techniques $(P<.05)$, as can be seen in Table 1 . The proposed technique did not differ $(P>.05)$ to evaluate morphological defects when compared with the usual techniques (DIC, Karras, E/N). However, when other Dip Quick Stain technique was used, some morphological defects (abnormal heads, abnormal middle piece, proximal droplet, and distal droplet) were not as well evaluated when compared with the usual techniques $(P<.05)$. The visualization of spermatozoa was sharper in the technique proposed in this study, when compared with Dip Quick, which is shown in Fig. 1.

The technique proposed in this study enables acrosome visualization only when it was partially detached, differently the Karras and DIC techniques that distinguish the cells with and without acrosome $(P<.05)$, as shown in Table 1 . In other techniques (E/N, Dip Quick 5', and Dip Quick), it was not possible to observe the spermatozoa acrosome.

A high correlation was observed $(P \geq .7)$ among techniques in the evaluation of total number of defects. But, when specific sperm defects of each segment were measured, some techniques showed better identification than others. The proposed technique showed a high correlation when compared with usual techniques (DIC,

Table 3

Correlation of acrosome evaluation results of equine spermatozoa between different techniques.

\begin{tabular}{llll}
\hline Technique & DIC & Karras & Dip Quick Modified \\
\hline DIC & 1.0 & & \\
Karras & 0.9706 & 1.0 & \\
Dip Quick Modified & 0.3154 & 0.3102 & 1.0 \\
\hline
\end{tabular}

Abbreviations: DIC, differential interference contrast microscopy; Karras, Karras modified stain.
Karras, E/N), as shown in Table 2. A clear view of the sperm cell was observed in classical evaluation techniques (DIC, Karras, E/N) (Fig. 2), and also in the technical proposal in the present study (Dip Quick Modified).

For acrosome defects, there was a high correlation between the techniques of Karras and DIC, but a low correlation when compared with the Dip Quick Modified technique (Table 3).

\section{Discussion}

Among the methods that can be used to assess sperm morphology, DIC is the most accurate and sensitive method, especially when evaluating major defects, such as acrosome, cytoplasmatic droplets, head defects, vacuoles [9]. This technique is superior to the usual, because it allows the visualization of all the constituent parts of the sperm cell [5]. However, it is a technique requiring a high equipment cost, and most often unfeasible for most professional, particularly those working on stud farms.

The most common technique used by practitioners is the evaluation in bright-field microscopy, which requires completion of stained smears. Accordingly, the diversity of staining patterns available provides different manners of sperm evaluation, evidencing areas of the sperm cell to be studied. Karras modified staining [6] and E/N showed efficiency in morphology evaluation.

The Dip Quick Stain is commonly used in laboratory routines to stain various types of slides, such as endometrial and vaginal cytology, blood smears, among others $[10,11]$. It is a stain easy to purchase with low cost. Viu et al [12] obtained good results in the evaluation of the percentage of defective sperm morphology in cattle when they used the Dip Quick Stain in wet preparation, observed in optical microscopy and compared the evaluation results in phase-contrast microscopy.

Likewise, Marques et al [13] described the efficient use of Dip Quick technique as stain to bovine semen smears. However, for the evaluation of equine spermatozoa, the Dip Quick Stain is not sensitive, mainly to classify head defects, middle piece, and acrosome [5], the results are similar to those reported in this study, particularly in assessing cytoplasmic droplets.

The increased exposure of the smears to solutions of Dip Quick Staining has been described for the evaluation of canine semen [14]. Pozor et al [8] also noted increasing improvement in the visualization of the equine sperm cell 
counters, along the exposure time of the smear on stains (5 minutes, 15 minutes, 30 minutes). Nevertheless, the great time necessary to achieve this staining technique become difficult to accomplish.

In the present study, Pozor et al's technique [8] was tested using the shortest time: 5 minutes. This was effective for the visualization of normal cells, the total number of morphological defects and individual defects except proximal cytoplasmic droplets and head defects, which evaluation was undermined by this technique and may explain the high impressions of detached heads, because the defects in that region could not be well evaluated with this technique, thus only considering as normal detached head. Probably with longer exposure to the stains, as demonstrated in their study, occurs an improvement in the preview of the spermatozoa contours, enabling visualization of these defects. The modification of Dip Quick Stain procedures with the elimination of washes between the stain allowed a longer exposition to each stain, improved the accuracy of visualization of most morphological alterations compared with the technique proposed by Pozor et al [8].

Runcan et al [15] evaluated the acrosome from equine spermatozoa, comparing the stain fluorescein isothiocyanate-conjugated peanut lectin-Pisum sativum agglutin with two commercial methods: Dip Quick and Spermac (Minitube, Madison). Differently of the present study, the slides used were immersed for 30 minutes in each step of Dip Quick. Concluding that all the three methods were considered efficient and high correlated for acrosome evaluation: intact and reacted.

The acrosome visualization was not efficient in the proposed technique because despite being possible its determination in some cells, this technique could not differentiate spermatozoa with and without acrosome, preventing its use for this purpose. Although Pozor et al [8] reported that the morphology of the cranial region of stallion spermatozoon can be evaluated clearly when the smear stays 30 minutes in each stain, but no cell with abnormal acrosome was detected in the study.

\section{Conclusion}

Based on the results of this study, it can be concluded that the proposed modification of Dip Quick Stain improved the accuracy of this technique when compared with the usual Dip Quick technique. However, this is inappropriate for assessing acrossomal integrity of sperm cells of this species.

\section{Acknowledgments}

None of the authors have any conflict of interest to declare.

\section{References}

[1] Arruda RP, Celeghini ECC, Alonso MA, Carvalho HF, Oliveira LZ, Nascimento J, Silva DF, Affonso FJ, Lemes KM, Jaimes JD. Methods of the assessment of morphology and function of sperm: actual moment and future challenges. Rev Bras Reprod Anim 2011;35: $145-51$.

[2] Rao Veeramachaneni DN. Spermatozoal morphology. In: . In: McKinnon AO, Squires EL, Vaala WE, Varner DD, editors. Equine reproduction. 2nd ed., vol. 126. Ames: Blackwell Publishing; 2011. p. 1297-307

[3] Johnson W. The significance to bull fertility of morphologically abnormal sperm. Vet Clin North Am 1997;13:255-70.

[4] Celeghini ECC. Efeitos da criopreservação do sêmen bovino sobre as membranas plasmática, acrossomal e mitocondrial e estrutura da cromatina dos espermatozóides utilizando sondas fluorescentes. 186f. Tese (Doutorado em Medicina Veterinária)-Faculdade de Medicina Veterinária e Zootecnia. São Paulo, SP: Universidade de São Paulo; 2005.

[5] Brito LFC, Greene LM, Kelleman A, Knobbe M, Turner R. Effect of method and clinician on stallion sperm morphology evaluation. Theriogenology 2011;76:745-50.

[6] Papa FO, Alvarenga MA, Carvalho IM, Bicudo SD, Ramires PRN, Lopes MD. Coloração espermática segundo Karras modificado pelo emprego de Barbatimão (Stryphnodendrum barbatiman). Arq Bras Med Vet Zootec 1988;40:115-23.

[7] Hancock JL. A staining technique for the study of temperature shock in semen. Nature 1951;167:323-4.

[8] Pozor MA, Zambrano GL, Runcan E, Macpherson M. Usefulness of Dip Quick Stain in evaluating sperm morphology in stallions. Proc Am Ass Equine Practnrs 2012;58:506-10.

[9] Freneau GE, Chenoweth PJ, Ellis R, Rupp G. Sperm morphology of beef bulls evaluated by two different methods. Anim Reprod Sci 2010;118:176-81.

[10] Alvarenga MA, Iwana De Matos MC. Utilização da escova ginecológica cytobrush na coleta de material endometrial de éguas. Arq Bras Med Vet Zootec 1990;42:67-8.

[11] Edens M. Heath breeding management in the bitch. In: Root Kustritz MV, editor. Small animal theriogenology. The practical veterinarian. St. Louis: Elsevier Science; 2003. p. 33-60.

[12] Viu MAO, Viu AFM, Rabelo RE, Romani AF, Ferraz HT, Santosand RE. Emprego de corante panótico na preparação de câmara úmida para avaliação da morfologia espermática em bovinos. Resumo do XVI Congresso Brasileiro de Reprodução Animal, 2005, Goiânia, Goiás, Brasil, CD-ROM.

[13] Marques LC, Spadetto RM, Lima DV, Serranoand DH, Sanglard GO. Utilização do corante Panótico Rápido ${ }^{\circledR}$ para avaliação da morfologia espermática de touros, 2013, XII SECOMV, Alegre-ES, CD-ROM.

[14] Johnson SD, Root Kustritz MV, Olson PNS. Canine and feline theriogenology. Philadelphia: Sounders; 2001. p. 287-306.

[15] Runcan EE, Pozor MA, Zambrano GL, Benson S, Macpherson ML Use of two conventional staining methods to assess the acrosomal status of stallion spermatozoa. Equine Vet J 2014;46: 503-6. 